Revue bibliographique pour le domaine irano-aryen

\title{
Pierre Briant. « À propos de l'« empreinte achéménide » (Achaemenid impact) en Anatolie. (Notes de lecture)»
}

\section{Rémy Boucharlat}

\section{(2) OpenEdition}

Journals

Édition électronique

URL : http://journals.openedition.org/abstractairanica/45511

DOI : 10.4000/abstractairanica.45511

ISBN : 1961-960X

ISSN : 1961-960X

Éditeur :

CNRS (UMR 7528 Mondes iraniens et indiens), Éditions de l'IFRI

\section{Référence électronique}

Rémy Boucharlat, «Pierre Briant. «À propos de l'« empreinte achéménide » (Achaemenid impact) en Anatolie. (Notes de lecture) » », Abstracta Iranica [En ligne], Volume 37-38-39| 2018, document 47, mis en ligne le 30 décembre 2018, consulté le 27 septembre 2020. URL : http://journals.openedition.org/ abstractairanica/45511; DOI : https://doi.org/10.4000/abstractairanica.45511

Ce document a été généré automatiquement le 27 septembre 2020

Tous droits réservés 


\title{
Pierre Briant. « À propos de l'« empreinte achéménide » (Achaemenid impact) en Anatolie. (Notes de lecture)»
}

\author{
Rémy Boucharlat
}

\section{RÉFÉRENCE}

Pierre Briant. « À propos de l'« empreinte achéménide » (Achaemenid impact) en Anatolie. (Notes de lecture)» in E. Winter, K. Zimmermann (eds.). Zwischen Satrapen und Dynasten. Kleinasien im 4. Jahrhundert v.Chr. Münster, 2015, p. 175-193, (Asia Minor Studien 76)

1 L'A. propose une réflexion méthodologique approfondie sur une question sans solution simple ni simpliste. L'empreinte achéménide est perceptible, rappelle l'A., par les traces de la «diaspora impériale » (les Perses dans les régions) et par les interventions de l'administration impériale et de ses représentants dans la vie quotidienne des populations de l'empire. Même au niveau d'une partie seulement de l'empire comme l'Anatolie, au demeurant une aire très vaste, la diversité des régions politico-culturelles et de leurs traditions respectives (internes à l'Anatolie, et augmentées de celles de la Grèce à l'ouest), rend l'évaluation de cet impact très difficile. Il est rendu encore plus complexe par les récentes études de sites (Sardes) ou de régions (Lydie, Carie, Lycie, Cilicie, etc.), les contributions à de nombreux colloques et les découvertes exceptionnelles des dernières décennies (cf. sur cette question : AI ce volume Elspeth R.M. Dusinberre, «Resistance, revolt and Revolution in Achaemenid Persia: Response »).

2 Parmi les exemples que cite l'A: une région, la prospection archéologique de la Paphlagonie, des monuments funéraires, une tombe monumentale et un sarcophage, 
sont des cas qui, selon le choix des auteurs, correspondent à un impact limité de l'empire (version "the elusive empire»), ou illustre l'œuvre d'un satrape ou d'un gouverneur perse, ou bien au contraire celle d'un membre de l'élite locale désireux de traiter sa tombe à la manière perse (l'art aulique achéménide). Il reste que ces documents restent marqués également par le style local et/ou parfois grec d'Asie Mineure. Mais il y a des exceptions, comme la reproduction fidèle ou parfois un peu grossière des modèles perses dans le Caucase. Cela ne répond pas à la question sur l'identité et la fonction des commanditaires, satrapes, gouverneurs, perses ou non, ou bien membres de l'élite locale. On touche dans cette région aux limites de l'apport de l'archéologie, sans croisement possible avec les données épigraphiques (absentes actuellement dans le Caucase) ou textuelles.

\section{AUTEURS}

\section{RÉMY BOUCHARLAT}

UMR 5133 CNRS-Université de Lyon 